\title{
EXPERIMENTAL INVESTIGATION \& CFD ANALYSIS OF AN SINGLE CYLINDER FOUR STROKE C.I. ENGINE EXHAUST SYSTEM
}

\author{
Rajesh Bisane $^{1}$, Dhananjay katpatal ${ }^{2}$ \\ ${ }^{l}$ Department of Mechanical Engineering, Kavikulguru Institute of Technology \& Science, Ramtek India \\ ${ }^{2}$ Department of Mechanical Engineering, Kavikulguru Institute of Technology \& Science, Ramtek India
}

\begin{abstract}
Each after treatment system design should be done in such a way that considering the complete system objectives. Energy efficient exhaust system development requires minimum fuel consumption and maximum utilization of exhaust energy for reduction of the exhaust emissions and also for effective waste energy recovery system such as in turbocharger, heat pipe etc. from C.I. engine. Traditional manifold optimization has been based on tests on Exhaust system. This trial \& error method can be effective but is very expensive \& time consuming. Beside this method cannot provide any information about the actual flow structure inside the system. This vital information can be obtained using 3-D CFD analysis. The design engineers can study the flow structures \& understand whether a particular system performs correctly or not.
\end{abstract}

Keywords - Engine Performance, Supercharged, Turbocharged, Exhaust System, CFD Analysis.

\section{INTRODUCTION}

Traditional manifold optimization has been based on tests on Exhaust system. This trial \& error method can be effective but is very expensive \& time consuming. Beside this method cannot provide any information about the actual flow structure inside the system. This vital information can be obtained using 3-D CFD analysis. The design engineers can study the flow structures \& understand whether a particular system performs correctly or not. The steady state and Quasi steady state analysis was performed in ANSYS CFX, from this we can get the flow structure, pressure drop temperature variation etc. higher the pressure drop higher will be the back pressure and there is power loss due to back pressure since piston has to overcome this pressure. So ultimate goal is to reduce the pressure drop in the exhaust system and make the necessary geometry changes [6]

The exhaust system of an IC engine has a significant influence on the global engine operation. In case of after treatment techniques, especially Diesel Particulate Filter, backpressure problem is a subject of specific interest for design and development of Particulate Matter emission control activities. In the present work, experimental analysis technique is used for determining the operating variables of compression ignition engines for effective exhaust system development. Backpressure on engine is controlled with the use of a specially designed diesel particulate filter during investigation. Among the different component of the system the exhaust Manifold has a paramount relevance on the gas exchange process. Though the intake system is dominant on the cylinder filling process, the exhaust manifold is able to influence the gas exchange process in several aspects, like the piston work during the exhaust stroke, the short-circuit of fresh charge from the intake into the exhaust and even the filling of the cylinder. In this sense, the most influential boundary condition imposed by the manifold is the pressure at the valve and especially the instantaneous pressure evolution. The mean backpressure is determined mainly by the singular elements, such as the turbine, the catalytic converter and the silencer. The instantaneous pressure evolution imposed by the manifold at the exhaust valve depends essentially on the layout and dimensions of the pipes, therefore an adequate design of the manifold geometry can improve the engine power and efficiency, and reduce the emissions of pollutants. Exhaust manifold design parameters are [12]

1) Minimum possible resistance in runners.

2) Properly design of Manifold geometry to reduce the pressure drop.

3) Eliminate the unnecessary turbulence \& eddies in the manifold.

\section{THE MATHEMATICS OF CFD}

The set of equations, which describe the processes of momentum, heat and mass transfer are known as the NavierStokes equations. These are partial differential equations, which were derived in the early nineteenth century. They have no known general analytical solution but can be discretized and solved numerically. Equations describing other processes, such as combustion, can also be solved in conjunction with the Navier-Stokes equations. Often, an approximating model is used to derive these additional equations, turbulence models being a particularly important example. There are a number of different solution methods, which are used in CFD codes. The different packages for CFD analysis are CFD-RC, FLUENT, STATCD, FLUENT and CFX. In this technique, the region of interest is divided into small sub regions, called control volumes. The equations are discretized and solved iteratively for each control volume. As a result, an approximation of the value of each variable at specific points throughout the domain 
can be obtained. In this way, one derives a full picture of the behavior of the flow [1][2][3]

\subsection{Governing Equations in CFD}

All of Computational Fluid Dynamics, in one form or other is based on fundamental governing equations of fluid dynamics,

$>$ Continuity Equation,

$>$ Momentum Equation

$>$ Energy Equation.

These equations speak physics of fluid flow. They are the mathematical statements of three fundamental physical principles upon which all fluid dynamics is based 1 and 2 .

\subsubsection{Continuity Equation}

It is based on the principle of conservation of mass.

Net mass flow out of control volume $=$ Time rate of decrease of mass inside control volume

Mass Conservation Equation

$$
\frac{\partial p}{\partial t}+\nabla(\rho u)=s_{m}
$$

\subsubsection{Momentum Equation}

It is based on the law of conservation of momentum, which states that the net force acting in a fluid mass is equal to change in momentum of flow per unit time in that direction. The force acting on a fluid element mass ' $\mathrm{m}$ ' given by Newton's second law of motion is

$$
\boldsymbol{F}=\boldsymbol{m} * \boldsymbol{a}
$$

Where ' $a$ ' is the acceleration acting in the same direction as force $F$

Momentum Equation

$$
\frac{\partial(\rho \underline{u})}{\partial t}+\nabla \cdot(\underline{\underline{u u}})=-\nabla P+\nabla \cdot \underline{\underline{\sigma}}+\rho \underline{g}+\underline{S}_{m o m}
$$

\subsubsection{Energy Equation}

It is based on the principle that total energy is conserved.

Total energy entering control volume $=$ Total Energy leaving Control volume

Energy Equation

$$
\frac{\partial(\rho e)}{\partial t}+\nabla \cdot(\rho \underline{u} e)=P \nabla \cdot \underline{u}+\nabla \cdot k \nabla T+\mu \Phi+S_{e}
$$

Where,

$$
\begin{array}{ll}
\partial=\text { Partial derivative } & \rho=\text { Mass density } \\
\partial=\underline{u}=\text { Velocity } & S=\text { Source } \\
t=\text { Time } & \Phi=\text { Viscous dissipation } \\
g=\text { Gravitational acceleration } & T=\text { Temperature } \\
\bar{e}=\text { Specific internal energy } & \mu=\text { Viscosity } \\
k=\text { Thermal conductivity } & \text { mom = Momentum }
\end{array}
$$

\section{EXPERIMENTAL SETUP}

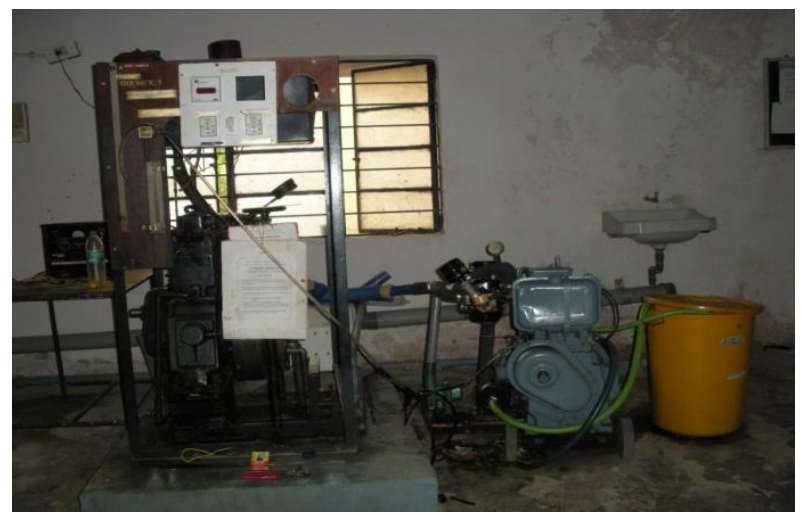

Fig 1: Super-Turbocharged Test Rig

\subsection{Engine Specification}

\begin{tabular}{|l|l|}
\hline Parameter & Specifications \\
\hline Engine & 4 S C I Engine \\
\hline Make & Kirloskar \\
\hline BHP & $5 \mathrm{KW}$ \\
\hline rpm & 1500 \\
\hline Fuel & Diesel \\
\hline Cooling & Water Cooling \\
\hline Bore & $0.08 \mathrm{~m}$ \\
\hline Stroke & $0.11 \mathrm{~m}$ \\
\hline Starting & Crank \\
\hline Method of ignition & C I \\
\hline Injection & Direct injection \\
\hline Orifice diameter & $0.02 \mathrm{~m}$ \\
\hline Cd for orifice & 0.62 \\
\hline
\end{tabular}

\section{METHODOLOGY}

The experimental evaluation carried out on single cylinder $4 \mathrm{~S}$ diesel engine then it is modified by supercharged engine, turbocharged engine and combination of both. For exhaust analysis the experimental values of pressure, temperature at inlet \& outlet condition of exhaust system is find out using gauges and temperature sensors and calculating velocity and mass flow rate at inlet \& outlet, Then exhaust system is design on ANSYS GAMBIT import for analysis and finding the CFD results which then compared with experimental. Through CFD analysis conclusion made on pressure 
variation, temperature variation flow structure, combustion $\&$ back pressure analysis.

\section{CFX ANALYSIS}

\subsection{Overview of CFX}

CFX is the software used for modeling fluid flow and heat transfer in complex geometries. It provides complete mesh flexibility, including the ability to solve your flow problems using unstructured meshes that can be generated about complex geometries with relative ease. It is written in the $\mathrm{C}$ computer language and makes full use of the flexibility and power offered by the language. Consequently, true dynamic memory allocation, efficient data structures, and flexible solver control are all possible.

All functions required to compute a solution and display the results are accessible in CFX through an interactive, menudriven interface. The basic procedural steps for solving a problem in CFX include:

1) Define the modeling goals.

2) Create the model geometry and grid.

3) Set up the solver and physical models.

4) Compute and monitor the solution.

5) Examine and save the results

6) Consider revisions to the numerical or physical model parameters, if necessary

CFX can model flow involving moving reference frames and moving cell zones, using several different approaches, and flow in moving and deforming domains(dynamic meshes). Solving flows in moving reference frames requires the use of moving cell zones. Problems that can be addressed include flow in a (single) rotating

Frame and flow in multiple rotating and/or translating reference frames. However in case of turbo machinery fluent uses multiple reference frame model, mixing plane model and sliding mesh model. [6]

\subsection{Modeling of Exhaust System}

The geometry model of exhaust Manifold is made in Gambit Package. The coordinates are provided for the development of the 2D model of the exhaust system. The model is then rotated about 360 degrees to get the $3 \mathrm{D}$ profile. For design purposes, the diffuser can be seen as an assembly of three separate sections operating in series a short parallel section and the diverging section. The short parallel section of the system acts as a casing to the engine. The straight portion of the diffuser helps in reducing the non-uniformity of flow, and in the diverging section, the pressure recovery takes place. The geometrical specifications of the diffuser have chosen somewhat arbitrarily, diameter of diffuser inlet $0.0254 \mathrm{~m}$ and diameter of the engine outlet $0.15 \mathrm{~m}$.

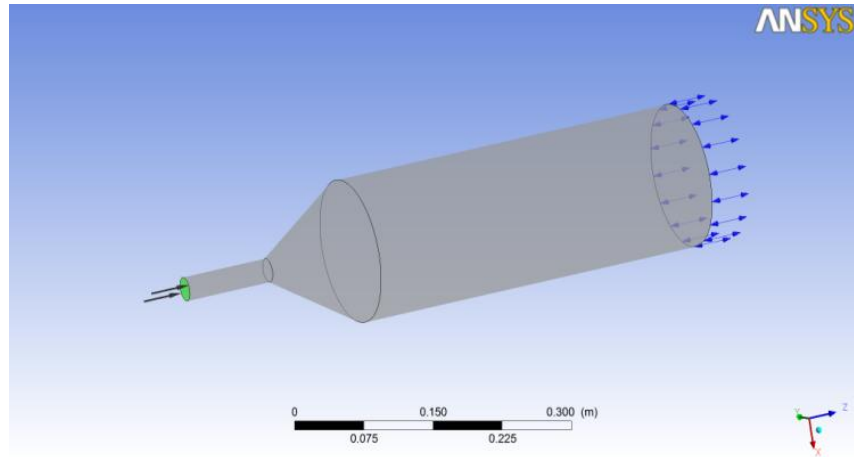

Fig 2: Domain of Exhaust System.

\subsection{Assumptions made in CFD Analysis}

1. Steady state analysis

2. Static Pressure ,Subsonic flow

3. Adiabatic wall surface

4. Domain surface is used as a wall with 'No Slip condition'

5 Inbuilt properties of air considered.

$65 \%$ turbulence intensity at inlet of air

\begin{tabular}{|l|l|}
\hline Parameter & ANSYS CFX \\
\hline Domain of simulation & Exhaust Manifold \\
\hline Turbulence model & k- $\varepsilon$ \\
\hline Heat Transfer model & Thermal Energy \\
\hline Fluid & Air Ideal gas \\
\hline Reference Pressure & 1 atm. \\
\hline Inlet & Mass flow\& Temperature of Fluid \\
\hline Outlet & Static pressure \\
\hline Discretization & High Resolution \\
\hline Residual Type & RMS \\
\hline Residual Target & $1 \mathrm{e}-04$ \\
\hline
\end{tabular}

\subsection{Mesh Model of Exhaust System}

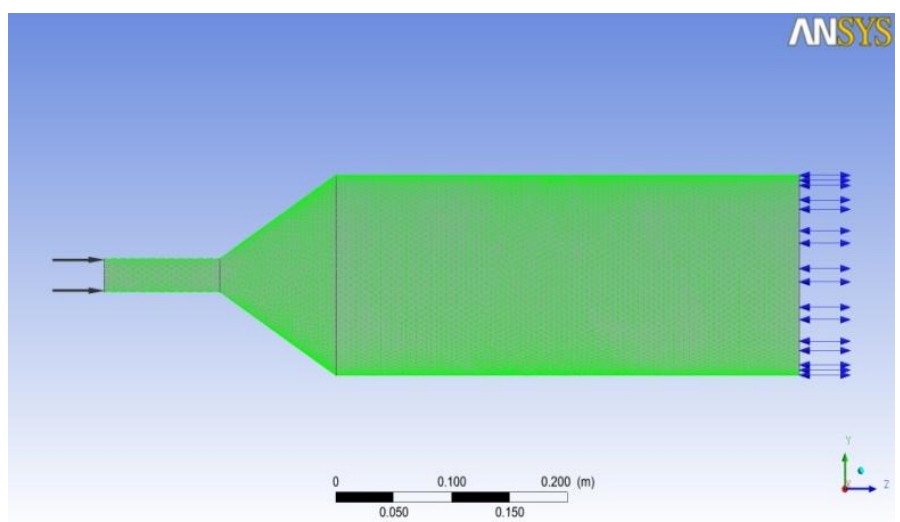

Fig 3: Meshing of Exhaust System

\begin{tabular}{|l|l|}
\hline Parameter & Details \\
\hline 1.Global Mesh Size & $5 \mathrm{~mm}$ \\
\hline 2.Surface Mesh Size & $5 \mathrm{~mm}$ \\
\hline 3. Curve Mesh Size & $5 \mathrm{~mm}$ \\
\hline 4.Mesh Type & Tetra-Hydra \\
\hline 5.No.of Elements & 386152 \\
\hline
\end{tabular}


6.No.of Nodes 70171

\section{NUMERICAL SIMULATION}

\subsection{CFD Analysis of Conventional Engine}

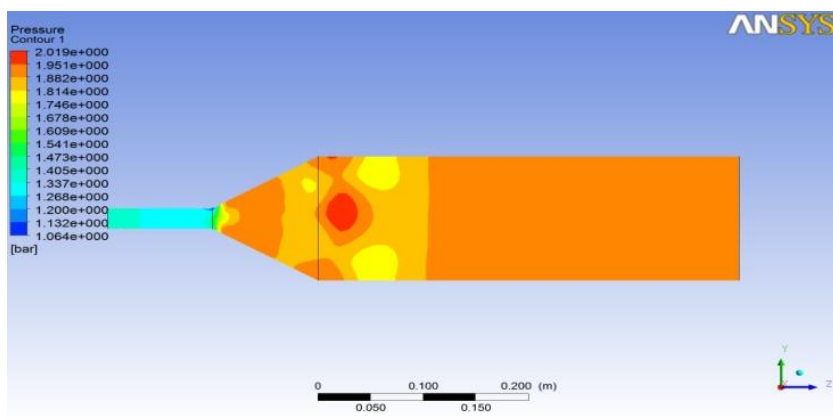

Fig 4: Pressure Contour of Conventional Exhaust System

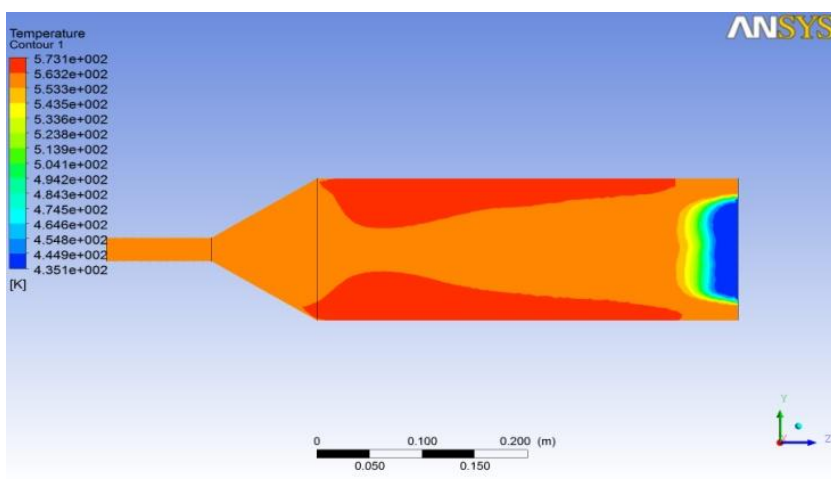

Fig5: Temp. Contour of Conventional Exhaust System

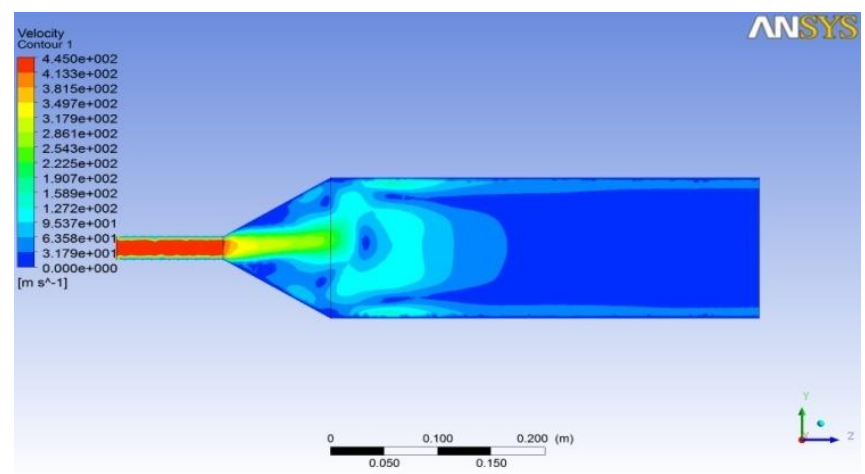

Fig6: Temp Contour of Conventional Exhaust System

\subsection{CFD Analysis of Turbocharged Engine}

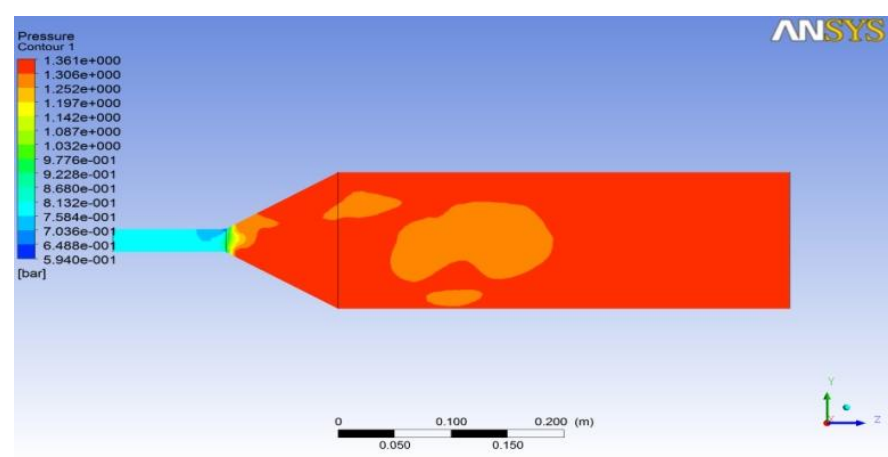

Fig 7: Pressure Contour of Turbocharged Exhaust System

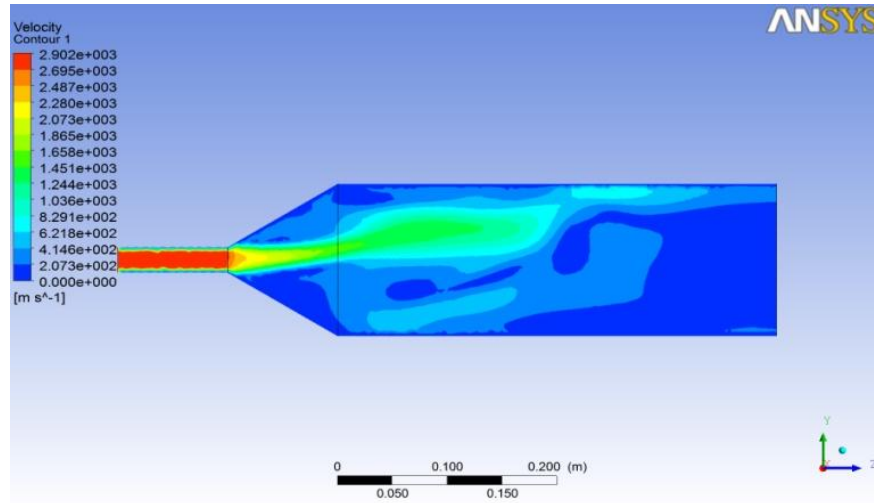

Fig 8: Velocity Contour of Turbocharged Exhaust System

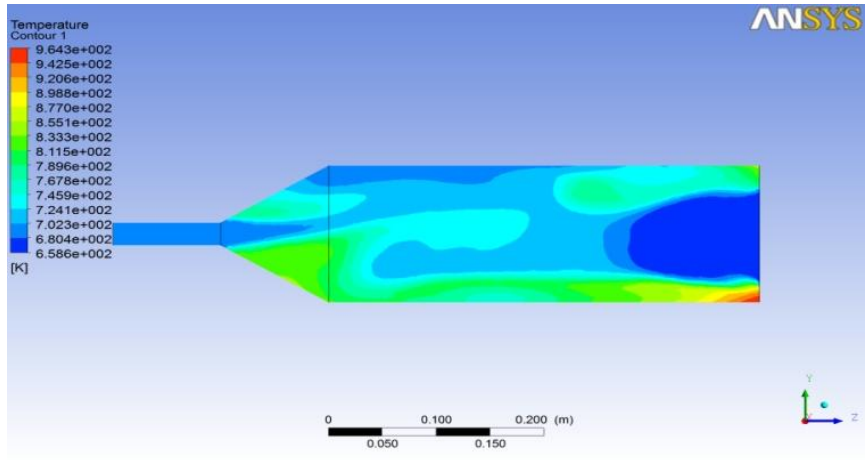

Fig 9: Temp. Contour of Turbocharged Exhaust System

\subsection{CFD Analysis of Supercharged Engine}

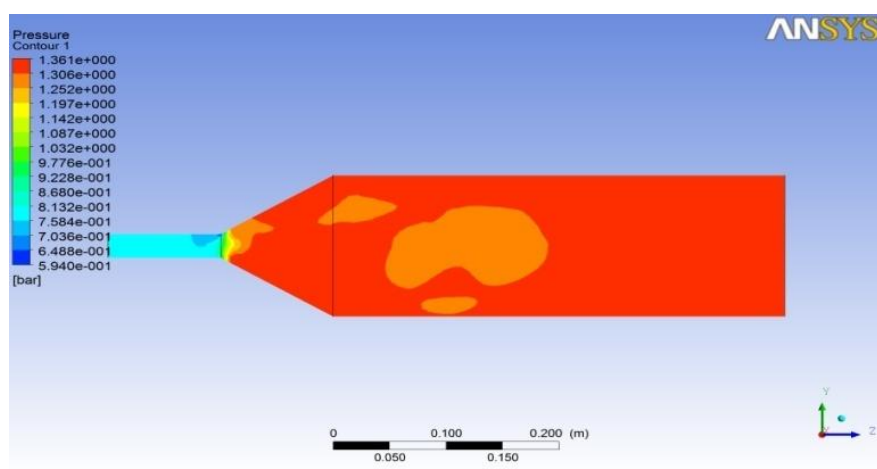

Fig10: Temp. Contour of Supercharged Exhaust System

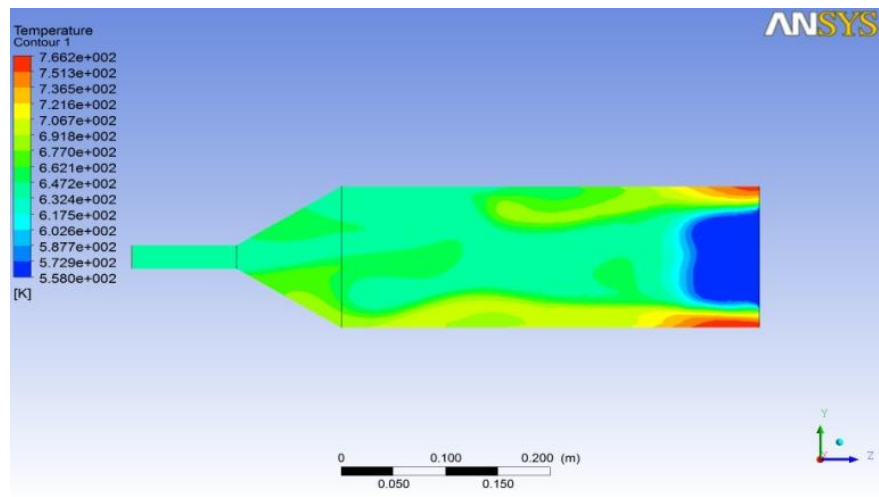

Fig11: Temp. Contour of Supercharged Exhaust System 


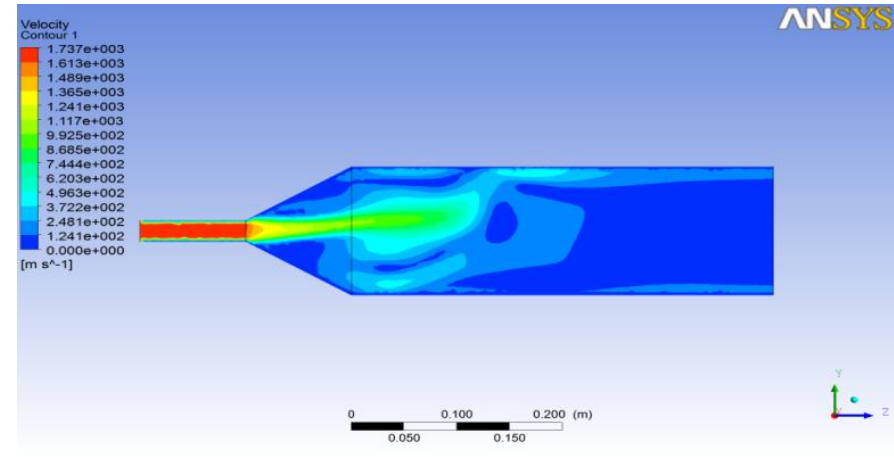

Fig 12: Velocity Contour of Supercharged Exhaust System

\section{BOUNDARY CONDITIONS}

\subsection{Conventional Engine}

The boundary conditions for conventional engine at inlet condition mass flow rate is $0.00749 \mathrm{~kg} / \mathrm{s}$ at temperature 562 $\mathrm{K}$ whereas at outlet opening pressure is maintained at 1.325 bar at temperature $353 \mathrm{~K}$., at surface the wall is smooth and adiabatic.

\subsection{Turbocharged Engine}

The boundary conditions for turbocharged engine is maintained at inlet condition mass flow rate is $0.0115 \mathrm{~kg} / \mathrm{s}$ at temperature $686 \mathrm{~K}$ whereas at outlet opening pressure is maintained at 2.89 bar at temperature $669 \mathrm{~K}$., at surface the wall is smooth and adiabatic.

\subsection{Supercharged Engine}

For supercharged engine the boundary conditions are taken as inlet the mass flow rate is $0.014 \mathrm{~kg} / \mathrm{s}$ at temperature 637 $\mathrm{K}$ whereas at outlet opening pressure is maintained at 2.94 bar at temperature $573 \mathrm{~K}$., at surface the wall is smooth and adiabatic.

\subsection{CFD RESULTS}

\subsection{CFD Results of Conventional Engine}

\begin{tabular}{|l|l|l|}
\hline Location & Inlet & Outlet \\
\hline Gauge Pressure (Bar) & 1.337 & 1.82 \\
\hline Velocity $(\mathrm{V})(\mathrm{m} / \mathrm{s})$ & 4.439 & 3.172 \\
\hline Temperature $(\mathrm{T})\left({ }^{\circ} \mathrm{K}\right)$ & 563 & 444 \\
\hline
\end{tabular}

\subsection{CFD Results of Turbocharged Engine}

\begin{tabular}{|l|l|l|}
\hline Location & Inlet & Outlet \\
\hline Gauge Pressure $($ Bar $)$ & 7.58 & 1.36 \\
\hline Velocity $(\mathrm{V})(\mathrm{m} / \mathrm{s})$ & 2.69 & 0.56 \\
\hline Temperature $(\mathrm{T})\left({ }^{\circ} \mathrm{K}\right)$ & 702 & 658 \\
\hline
\end{tabular}

\subsection{CFD Results of Supercharged Engine}

\begin{tabular}{|l|l|l|}
\hline Location & Inlet & Outlet \\
\hline Gauge Pressure $($ Bar $)$ & 8.13 & 1.30 \\
\hline Velocity $(\mathrm{V})(\mathrm{m} / \mathrm{s})$ & 1.73 & 1.24 \\
\hline Temperature $(\mathrm{T})\left({ }^{\circ} \mathrm{K}\right)$ & 632 & 558 \\
\hline
\end{tabular}

\section{CONCLUSIONS}

This paper has presented a powerful method to evaluate exhaust system performance. Traditional method of optimization by experiments is time consuming and expensive. Also it does not give the flow structure. CFD simulation is a powerful method to give flow structure, pressure variation, temperature variation and velocity variation in the flow domain. The procedure and results of both steady state and quasisteady state analysis have been explained and CFD results are experimentally validated for steady state and quasisteady state analysis. From the results of it we are getting the flow structure. According to these results geometry is modified. Steady state analysis is carried out on each modified geometry since steady state analysis is faster and gives better results. The geometry, which gives minimum pressure drop and hence minimum backpressure, is the optimized geometry. This is done by trial and error method. Again for the optimized geometry CFD results would be validated by experimentation, hence the supercharged and turbocharged system can be efficiently employed for increasing performance of engine. Also the Non-dimensional stiffness rigidity is sufficiently high. Finally it can be stated that 3-D CFD simulation can be used as a strong and useful tool for design or optimization of exhaust system.

\section{REFERENCES}

[1] John D. Anderson, Jr., "Computational fluid dynamics - The basic with applications", McGraw Hill international Editions 1995.

[2] H. K. Versteeg \& W. Malasekera, " An introduction to Computational fluid dynamics - The finite volume method “, Long man Scientific \& Technical, Long man Group Ltd. Ed. 1995.

[3] C. T. Shaw, "Using Computational Fluid dynamics", Prentice Hall, 1992.

[4] H. M. Gousha, "Fuel system \& Emission Controls" Second Edition Harper Collins Publisher. 1988.

[5] V. Ganeshan, "Internal Combustion Engines", Tata McGraw-Hill. 2006.

[6] Atul A Patil \& Dr.L.G.Navale" "Computational Fluid Dynamics Analysis Of Energy Efficient Exhaust System Using Fluent”ESRHRE Vol.1-2012-130-136

[7] M. Safari \& m. Ghamari, A. Nasirtosi, " Intake Manifold Optimization by using 3-D CFD Analysis", SAE paper 2003-32-0073.

[8] Meda Lakshmikantha \& Mathias Keck, " Optimization of Exhaust Systems ", SAE paper 200201-0059.

[9] NeginMoffouni\& Reza Ebrahimi, SiamacHossein Pour, " The effect of Intake Manifold Runners Length on the volumetric Efficiency by 3D CFD Model", SAE paper 2006-32-0118.

[10] J. Benojes, E. Royes, V. Bermuder\& J. R. Serrano,'Pre-Design Criteria for Exhaust Manifolds in I.C. Automotive Engines", SAE paper 980783.

[11] David Tueddell, Clayton Sloss\& Thomas Werner, " An Advanced CFD simulation strategy for Exhaust Manifolds with Close - Coupled Catalytic 
converters", SAE paper 2005-01-1922.

[12] R. H. McKee, G. McCullough, G. Cunningham, J. O. Taylor, N. McDowell, J.T. Taylor \& R. McCullough. " Experimental Optimization of Manifold and Camshaft Geometries for a Restricted 600cc four cylinder, four - stroke engine " SAE paper 2006-320070.

[13] P. O. Santacreu, O. Cleizergues\& C. Simon, P. Duroux, " Design of stainless steel Automotive Exhaust Manifolds" SAE paper 2003-01-2848.

[14] Christian fyhr \& OlofDabiberg, "Complete Engine Modeling Using CFD", SAE paper 2004-01-0109.

[15] F. Fortuhato\& F. Quadrini, S. Bova, " Catalyst Light - off Evaluation Using CFD Simulation of Exhaust Manifold", SAE paper 2005-01-3895.

[16] E. Navarro Arevalo, s. Ramirez de la Piscina Milan, " Optimization of Exhaust Manifold, for a multicylinder Turbocharged two - stroke diesel engine.

[17] Z. Jason. Hou\& Ted Angelo, " A new CFD model for Understanding \& managing diesel Particulate Filter Regeneration ", 10th Diesel Engine Emission Reduction Conference Aug. 29-Sept. 2,2004.

[18] PrabirDatta, Richard Liddy, " Correlation Study of Exhaust Manifolds - Lab Test Results Vs Customer fleet Results, SAE paper 2002-01-1317.

[19] Sophie Salasc, EdouardBarrieu\& Vincent Leroy, " Impact of Manifold design on Flow distribution of a close - coupled catalytic converter, SAE paper 2005-01-1626.

[20] Han-Scng Kim, Kyoung - Min Cho, " A study of flow characteristic Inside the two types of Exhaust Manifold \& CCC Systems", SAE paper 1999-010457.

[21] Mansarunomato, " The effect of geometry on stiffness and deformation in Exhaust Manifolds for inline four Cylinder Engines", SAE paper 2003-010409.

[22] J. Ling \& L.T.Y.Tun,"CFD Analysis of Non symmetrical Intake Manifold for formula SAE car ", SAE paper 2006-01-1976.

[23] http: //www.ansys.com/CFX.

[24] Ansys ICEM CFD/ AI. Environment Help Manual 13.0

\section{BIOGRAPHIES}

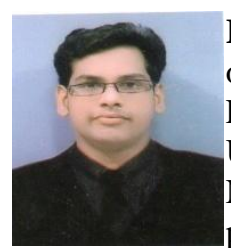

Rajesh Bisane is a student of final semester of P.G course in Engineering (Heat Power Engineering) of KITS at Ramtek, Nagpur University, India. . He has published 05 National level technical papers, 01 technical paper in International Conference and 01 paper in International Journal. He won first prize in project competition at IIT Bombay 2010 and is a Life Member of ISTE,

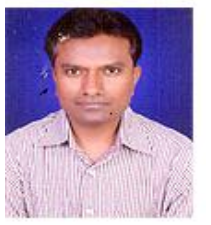

Dhananjay Katpatal is an Assistant Professor at KITS, Ramtek in the Mechanical Engineering Department. He has 12 years teaching experience. He has published 06 technical papers in national \& International Conference and is a Life Member of ISTE, SAE, and Associate Member of Institute Engineers. He is pursuing PhD from VNIT Nagpur, India. 